\title{
A general equilibrium analysis on the impacts of regional and sectoral emission allowance allocation at carbon trading market
}

Published in: Journal of Cleaner Production 192 (2018) 421-432, https://doi.org/10.1016/j.jclepro.2018.05.006

Zhongjue Yu ${ }^{a}$, Yong Geng ${ }^{a, b, e *}$, Hancheng Dai ${ }^{c, t}$, Rui Wu ${ }^{d}$, Zhiqing Liu ${ }^{a}$, Xu Tian

a, Raimund Bleischwitz ${ }^{\dagger}$

a School of Environmental Science and Engineering, Shanghai Jiao Tong University, No. 800 Dongchuan Road, Minhang, Shanghai, 200240, China

${ }^{\mathrm{b}}$ China Institute for Urban Governance, Shanghai Jiao Tong University, No. 800 Dongchuan Road, Minhang, Shanghai, 200240, China

${ }^{c}$ College of Environmental Science and Engineering, Peking University, Beijing 100871, China.

d School of Business, Nanjing Normal University, No. 1 Wenyuan Road, Nanjing 210023, China

${ }^{e}$ School of Finance and Economics, Jiangsu University, No. 301 Xuefu Road, Zhenjiang 212013, China

' University College London, Institute for Sustainable Resources, Central House, 14 Upper Woburn Place, London WC1H ONN, United Kingdom

*Corresponding author:

Yong Geng: ygeng@sjtu.edu.cn Telephone: +86-21-54748019, Fax: +86-21-54740825

Hancheng Dai: dai.hancheng@pku.edu.cn; Tel: +86-10-62764974; Fax: +86-10-

62764974

Abstract: It is critical to adapt to climate change and reduce the overall carbon emissions. China announced its Nationally Determined Contributions (NDC) at the Paris climate conference in 2015. The carbon cap-and-trade scheme, which plays a key role in carbon emissions abatement, is an effective policy for China to achieve its NDC. This study focuses on the allocation of regional and sectoral initial carbon emission allowances in Shanghai. An impact evaluation on the macro-economy, carbon trading markets and participating sectors for the year 2030 was conducted by applying a computable general equilibrium (CGE) model. The results show that the carbon cap-and-trade scheme would cause a 3.4\% GDP loss and an 8.9\% welfare loss in 2030. The carbon price would be $161.2 \mathrm{USD} / \mathrm{t}$ and $147.2 \mathrm{USD} / \mathrm{t}$ under the two representative scenarios. The 
allocation of initial allowances would have a significant impact on both carbon market scale and sectoral trading behaviors. The power generation sector and the petrol oil sector would undertake the greatest output loss, while the metal smelting sector would become the main seller. Furthermore, the initial allowances allocation under a certain abatement target would hardly affect sectoral production but remarkably affect trade behaviors at the carbon trading markets.

Key words : Emission trading scheme; Allowance allocation; Computable general equilibrium model; Urban governance; Shanghai

\section{Introduction}

It has been widely accepted by the global community that human activities are continuously damaging the ecological system and are the key drivers on climate change (Pachauri et al., 2014). China has made great efforts to cooperate with the global community to address this challenge by ratifying the Paris Agreement and announcing the Nationally Determined Contributions (NDC), which intends to lower carbon emissions intensity, namely carbon dioxide $\left(\mathrm{CO}_{2}\right)$ emission per unit of Gross Domestic Product (GDP) by $60-65 \%$ from the 2005 level in 2030 and peak the $\mathrm{CO}_{2}$ emission by 2030 (Liu et al., 2018). To encourage the Chinese enterprises to cut their carbon emissions and seek a cost-effective pathway to achieve this NDC target, China proposed to establish a domestic carbon trading market in its $12^{\text {th }}$ Five-Year Plan. Since then, seven pilot carbon trading markets have been established in order to gain experiences for a nationwide carbon trading market that is planned to be built up in 2017 (Wang et al., 2015; Zhang et al., 2013). Until now, the cumulative trading volume of seven pilot carbon market is about 1,600 million ton (Mt) (ENVIRONOMIST et al., 2017). Recently, the national carbon trading market was established by the National Development and Reform Commission (NDRC) of China, enrolling only the electricity sector. According to the estimation of NDRC, the carbon market scale would be above 3 billion tons, exceeding those of any other countries or regions.

Shanghai, one of the seven pilot carbon markets, is the economic and financial center of China. It was chosen to become the transaction centre of China's national carbon trading market due to its strong financial industry. The pilot market in Shanghai includes 190 enterprises and covers 57\% of the total carbon emissions of the city (Wu et al., 2016b). The pilot market in Shanghai accounted for $16 \%$ of the total national trading volume, which was a relatively small scale compared to those leading provinces such as Hubei and Guangdong. However, Shanghai is the only provincial leveled municipality 
where all the participated enterprises perfectly comply with the allowance limits every year since the market was established (Exchange et al., 2017). Therefore, it is more stable and normative than other Chinese pilot markets.

Academically, several studies were conducted on the EU (Europe Union) and China carbon trading market. These studies can be categorized into two groups, namely focusing on the operating mechanism and the economic impact (Zhang et al., 2010). Studies in the first group paid attention to the EUETS (Europe Union Emission Trading Scheme) allowance price shock in 2007 when the price sharply dropped and almost reached zero, in which they uncovered that the reason for this disaster is the over-allocation of the allowance (Ellerman et al., 2008; Voorspools et al., 2006). Ellerman and his colleages (2006) proposed a new method on estimating the issue of overallocation and found that it had already taken place since 2005. Convery and his colleages (2008) found that despite the risk of over-allocation, the free allocation method had a lower impact on the participants' benefits and could be replaced by the auction method when the market is ready. Soleille and his colleages (2006) evaluated the efficiency of command-and-control and ETS methods as two different policy tools and found that the key to environmental efficiency is not the policy tool but the ambition of the overall carbon emissions abatement target.

Learning from the experience of EU-ETS, the establishment of the Chinese carbon market was based upon the free allocation method. This requires that such a market should be carefully designed to avoid over-allocation. Several provincial allowance allocation methods were proposed, including the one based on per capita GDP (Wu et al., 2016a), per capita equal historical cumulative emissions (Gao et al., 2015), and $\mathrm{CO}_{2}$ abatement capacity index (Wei et al., 2012). In addition, different opinions occurred, focusing on whether China should start the carbon market with the free allocation method or the auction method (Cong et al., 2012; Hübler et al., 2014). Other studies focusing on the operation mechanism paid attention on trading prices, having close relations with energy prices (Kanen et al., 2006) and policy making (Alberola et al., 2008a). For instance, several studies were conducted to evaluate the possible carbon price levels of China's carbon market although no unified results were achieved (Tang et al., 2016; Wang et al., 2015; Wu et al., 2016b).

From economic impact point of view, studies on EU-ETS mainly focus on the impact of ETS on one certain sector. For instance, Denny and his colleages (2009) found that the establishment of ETS would push the electricity sector to transform from coal to natural gas. Chen and his colleages (2008) revealed that the free allocation method brought extra benefits to the electricity sector and compensated its loss. Albers Albers and his colleages (2009) found that the ETS brought higher costs and pressures to the aviation sector in Europe, but 
would not cause a significant change in demand. Alberola and his colleages (2008b) analyzed the manufacturing industry participating in the EU-ETS and found during 2005-2007 the carbon price had not brought any significant impact on most manufacturing sectors. Furthermore, Jiang and his colleages (2016) investigated the Chinese carbon market by focusing on the impact of the establishment of the national carbon trading market. At the national level, the establishment of the national carbon trading market can promote regional coordination and low-carbon transition and reduce the carbon emissions abatement cost of the nation (Yu et al., 2011; Zhou et al., 2013). Moreover, carbon trade has a strong potential in reducing welfare loss and achieving social equilibrium (Tang et al., 2013). However, different provinces are facing different challenges and require region-specific policies (Zhang et al., 2013). At the sectoral level, several studies focused on the impact on the energy sectors and found that the national carbon trade would boost the electricity price and increase the proportion of renewable energy power plant (Cong et al., 2010), and effectively increase the benefit of energy sector (Chen et al., 2010). Li and his colleages (2014) pointed out that energy sector would play the key role in the nationwide carbon trading market and mitigation actions. At the enterprise level, Zhang and his colleages (2011) analyzed enterprises' strategies towards the national carbon trading market and proposed that enterprises should reduce their carbon emissions in order to seek maximum benefits. Finally, Xu and his colleages (2017) found that low-carbon products will be more competitive with the increasing carbon prices.

In general, the existing studies mainly focus on evaluating the nationwide impacts of carbon emissions trading market or investigate its hidden connection with the energy system in China. However, few studies focused on the economic impacts at both provincial and sectoral level. Although it is necessary to have such a national-leveled study, the allocation of initial allowances should be conducted at the provincial level so that each sector within one province can receive appropriate allowance. Without a careful design of such an allocation, it would be difficult to achieve the national mitigation target.

To fill such research gap, this study aims to investigate the economic impacts of the carbon emissions trading market by considering both provincial abatement targets and sectoral allowance allocations together. Also, the characteristics and behaviors of each sector will be investigated so that appropriate mitigation pathways for urban low carbon development can be identified.

The following research questions will be answered in this study: What would be the impact of future carbon market under the NDC target? How would the sectoral impacts vary under different abatement scenarios? Which 
sector would receive the greatest impact and which sector would have the largest abatement potential? How would each sector respond to the carbon cap and better utilize the carbon trade? In order to answer these questions, a two-region computable general equilibrium (CGE) model is applied.

This paper is organized as below. After this introduction section, the information about the CGE model, data sources and scenarios design are detailed in section 2. Section 3 presents the simulation results, including initial allowance allocations, macroeconomic impacts, carbon trading market impacts, sectoral trade and sectoral responses. Section 4 discusses policy implications. Finally, conclusions are drawn in section 5.

\section{Methods and data}

\subsection{The CGE model}

The CGE model could capture the full range of interaction and feedback effects between different agents in the economic system. It has been widely used to assess economic and environmental impacts of different climate policies at global (Fujimori et al., 2014, et al., 2015), national (Wang et al., 2009; Zhang et al., 1998) and provincial (Cheng et al., 2016; Cheng et al., 2015; Dai et al., 2012; Wang et al., 2015) levels.

The IMED/CGE (Integrated Model of Energy, Environment and Economy for Sustainable Development/Computable General Equilibrium) model applied in this study can be classified as a multi-sector, 2-region, recursive dynamic CGE model continuously developed by the Institute of Environment and Economy (IoEE) at Peking University. It includes Shanghai and the Rest of China (ROC) and covers 37 economic commodities and corresponding sectors (Table 1), which are classified into basic and energy transformation sectors. Major model features are similar to the one-region version (Dai et al., 2012), including a production block, a market block with domestic and international transactions, as well as government and household incomes and expenditures blocks. Activity output for each sector follows a nested constant elasticity of substitution (CES) production function. Inputs are categorized into material commodities, energy commodities, labors, capitals and resources. This CGE model is solved by Mathematical Programming System for General Equilibrium under General Algebraic Modeling System (GAMS/MPSGE) (Rutherford et al., 1999) at a one-year time step. Technical descriptions are provided in the Appendix and an up-to-date introduction is available at http://scholar.pku.edu.cn/hanchengdai/imedcge.

<insert Table 1 here $>$

For the purpose of this study, a carbon emissions trade module at the sectoral level was added to this CGE model. As Figure 1 illustrates, C1 and C2 are the demand curves of carbon emissions rights for sectors 1 and 2 when emission allowances Q1 and Q2 are allocated to each sector (or region) 
without carbon emissions trade. Such a CGE model determines equilibrium points, $A$ and $B$, with carbon shadow prices of $\mathrm{P} 1$ and $\mathrm{P} 2(\mathrm{P} 1<\mathrm{P} 2)$ for sectors 1 and 2, respectively. By contrast, when free carbon trade is allowed, an identical carbon trading market will be established. Sector (or region) 1 tends to sell Q1 unit of carbon emission rights to the market while sector (or region) 2 tends to purchase Q2 unit of carbon emission rights from the market. This CGE model will find a new equilibrium point, $A^{\prime}$ and $B^{\prime}$, with an identical carbon shadow price of $P^{\prime}$ that clears the carbon market by satisfying the conditions in Equations (1) and (2).

<insert Figure 1 here>

Carbon selling amount $\left(\Delta Q_{1}\right)$ equals purchasing amount $\left(\Delta Q_{2}\right)$, which is shown in Equation (1):

$$
\Delta Q_{1}=\Delta Q_{2}
$$

Expenditure of buyers $\left(\Delta \mathrm{Q}_{1} \mathrm{P}^{\prime}\right)$ equals revenue of sellers $\left(\Delta \mathrm{Q}_{2} \mathrm{P}^{\prime}\right)$, which is shown in Equation (2):

$$
\Delta \mathrm{Q}_{1} \mathrm{P}^{\prime}=\Delta \mathrm{Q}_{2} \mathrm{P}^{\prime}
$$

Correspondingly, when more sectors participate in carbon emissions trade, the above conditions will keep as shown in Equations (3) and (4).

Equation (3):

$$
\sum_{\mathrm{s}} \Delta \mathrm{Q}_{\mathrm{s}}=\sum_{\mathrm{b}} \Delta \mathrm{Q}_{\mathrm{b}}
$$

Equation (4):

$$
\sum_{s} \Delta \mathrm{Q}_{\mathrm{s}} \mathrm{P}^{\prime}=\sum_{\mathrm{b}} \Delta \mathrm{Q}_{\mathrm{b}} \mathrm{P}^{\prime}
$$

Where $s$ and $b$ represent sellers and buyers (either a sector or a region) in the carbon trading market, respectively; $Q$ represents carbon trading volume in tons; $P$ represents carbon shadow price.

\subsection{Shanghai's carbon emissions trading scheme}

Shanghai's ETS applies to enterprises with $\mathrm{CO}_{2}$ emissions over 20000 tons for industrial enterprises and 10000 tons for non-industrial enterprises. Smallscale enterprises are excluded. However, since both large and small-scale enterprises are included within one sector, all emissions from participating sectors are covered in this model, only sectors of ports, hotels, shopping malls and financial intermediation are excluded from ETS. In total, Shanghai's ETS includes 8 industrial sectors and 2 transport sectors (Table 2). In addition, this model only accounts for fossil fuels combustion related $\mathrm{CO}_{2}$ emissions.

$<$ insert Table 2 here $>$

\subsection{Scenarios setting}


First of all, the national abatement target is set to achieve the NDC, that is to say, the overall carbon emissions intensity will be reduced by $65 \%$ from the 2005 level in 2030. As a reference, there is a Business-as-Usual (BaU) scenario, where neither carbon cap nor carbon emissions trade exists. The setting details of the exogenous variables of the BaU are provided in Table 3.

<insert Table 3 here $>$

Other scenarios are divided into three groups.

(1) Whether carbon emissions trading exists:

CAP: Only carbon cap exists;

ET: Both carbon cap and carbon trade exist.

(2) Carbon emissions intensity reduction rate from 2005 level in 2030:

P55: Carbon emissions intensity of Shanghai will be reduced by 55\%;

P65: Carbon emissions intensity of Shanghai will be reduced by 65\%;

P75: Carbon emissions intensity of Shanghai will be reduced by $75 \%$.

(3) Sectoral allocation method

SHRbau: The initial allowance for each sector is allocated according to the proportion of its emission volume in the predicted data under the $\mathrm{BaU}$ scenario in 2030;

SHR07: The initial allowance for each sector is allocated according to the proportion of its emission volume in the historical data of the base year of 2007.

To simplify the analysis, P55ET SHRbau, P65ET SHRbau, P75ET SHRbau and P65ET SHR07 were chose as the representative scenarios. The details of scenarios setting are presented in Table 4.

$<$ insert Table 4 here $>$

\subsection{Data sources}

Data for this study come from different sources due to their complexity. The key sources include the input-output tables of Shanghai and China (NBS, 2007, 2012b), energy balance tables (NBS, 2008, 2012a), carbon emission factors of different fossil fuels (Eggleston et al., 2006). Energy prices of coal, oil and gas for the year of 2007 were used to populate the model (NBS, 2008, 2012a).

\section{Results}

\subsection{Sectoral allocations and carbon emission reductions}

Without the carbon cap, the total carbon emission of Shanghai will increase from 192.4 Mt in 2007 to $590.4 \mathrm{Mt}$ (BaU) in 2030, with a 207\% increase. In addition, carbon emissions intensity will achieve a 38\% increase from 1.20 $\mathrm{kg} / \mathrm{USD}$ in 2007 to $0.74 \mathrm{~kg} / \mathrm{USD}$ (BaU) in 2030 due to the scale effect and efficiency effect, although it is still far away from meeting the NDC target.

In terms of the allowances, according to the abatement target in the scenarios setting, the total allowances under the P55, P65 and P75 scenarios 
are 409.5, 366.2, 337.3 Mt, indicating that the total allowance will decrease when more stringent regional abatement targets are applied. Under a specific abatement target, the total allowances for SHRbau and SHRO7 scenarios are set to be identical, but the sectoral allocations are different due to different allocation methods. As shown in Figure 2, the power generation sector and the metal smelting sector receive the majority of the allowances under both SHRbau and SHR07 scenarios.

<insert Figure 2 here $>$

A carbon cap leads to emissions reduction in the IMED/CGE model. Taking P65ET SHRbau (see Figure 3) as an example, the abatement setting can result in a 38\% carbon emissions reduction to BaU. The emission volume is $366.2 \mathrm{Mt}$, which equals the total allowance of this scenario. The power generation sector accounts for the most (32.1\%), followed by the chemicals sector (14.7\%), the waterway sector (8.5\%), and the metal smelting sector (8.3\%). The carbon emissions intensity under the P65ET SHRbau scenario will be $0.47 \mathrm{~kg} / \mathrm{USD}$ in 2030, equivalent to a $65 \%$ increase from the 2005 level. It is worth mentioning that the total carbon emissions and carbon emissions intensities of different scenarios under a specific abatement target are respectively equal due to scenario settings, such as the P65ET SHRbau and P65ET SHR07.

$<$ insert Figure 3 here $>$

\subsection{Macro-economic impacts}

The simulation of the BaU scenario shows that in 2030, GDP will be 803.0 billion US dollar (bilUSD) and welfare (which is defined as the household consumption of goods and services with disposable income) will be 358.0 bilUSD. The carbon cap policy will inevitably hinder economic growth (see Figure 4), which is illustrated by the considerable loss of GDP and welfare under all the mitigation scenarios. The GDP and welfare loss will increase when the abatement target becomes increasingly stringent.

A considerable change takes place after establishing the carbon trading market. Both the GDP and welfare loss are alleviated when the carbon trade between different sectors is allowed. It is found that carbon trade can compensate for the macro-economic loss to a certain degree. According to the Coase(Coase et al., 1937), under the ET scenarios, those sectors with fewer potentials to cut their emissions can maintain their production rather than reduce their production by purchasing the allowances in the market released by those who prefer to sell their surplus allowances for extra benefits.

$<$ insert Figure 4 here $>$

In terms of the impact of different allocation methods (see Figure 4), the GDP loss under the SHR07 scenario (5.79\%) would significantly exceed the one under the SHRbau scenario (3.97\%) if carbon trading market is not established, but the losses under those two allocation methods would become similar after 
establishing the carbon trading market (3.41\% under SHRbau and $3.40 \%$ under SHR07). According to the above mentioned allocation methods, since the simulation year is 2030 , the pressures on carbon emissions abatement for all the participating sectors are the same under the SHRbau scenario, where the emission of each sector is set to decrease by the same rate from 2030. While the SHR07 method is based on the historical data of 2007, thus imbalance of carbon abatement pressure is expected to take place in 2030. However, when carbon trading market is established, the allowances will be reallocated through the market mechanism, which redresses the imbalance between the two allocation methods and brings the macroeconomic loss to a similar level. With this mechanism, the distorted impact of different allocation methods on macro-economy will be revised through the transaction of allowances.

\subsection{Carbon emissions abatement costs}

Under the scenarios where carbon caps exist, the CGE framework will endogenously generate a shadow price of carbon allowance for each sector no matter the carbon trading market is established or not. The prices will be different among sectors if the carbon trading market is not established, which are equal to the marginal costs of extra reduction beyond autonomous carbon emissions reduction, namely the carbon abatement cost. However, there will be only one identical price under each ET scenario because trade takes place between sectors with higher carbon abatement costs and sectors with lower ones, and eventually an equilibrium will be achieved, in which the final carbon price will take place under the coverage of different levels of sectoral abatement costs.

Figure 5 shows the relation between the carbon emissions abatement costs and autonomous carbon emissions abatement potential of the participating sectors. The carbon emissions abatement cost of each sector is represented on the $y$-axis. The autonomous carbon emissions abatement potential is represented by the sectoral carbon emissions intensity change from BaU (2030) to the base year (2007), presented on the x-axis. Additionally, the obtained initial allowance of each sector is presented by the bubble size of each sector.

<insert Figure 5 here>

The carbon emissions abatement cost of one sector depends on both exogenous and endogenous factors. Exogenous factors refer to how much extra carbon emissions reduction that is beyond the autonomous reduction level each sector is undertaking. Endogenous factors refer to technology, energy efficiency, energy mix, etc. (Wu et al., 2016b), which can be attributed to the scale effect and efficiency effect.

In terms of exogenous factors, by comparing the carbon emissions abatement cost and the obtained initial allowances of each sector, it can be 
concluded that a larger possession of initial allowance leads to a lower carbon emissions abatement cost, except for the aviation sector. Taking the metal smelting sector as an example, its carbon emissions abatement cost will even reach zero under the P65CAP SHR07. The zero abatement cost appears when the initial allowance of one sector exceeds the actual demand. In the case of metal smelting sector, the obtained initial allowance is $58.0 \mathrm{Mt}$ and the carbon emission under the corresponding CAP scenario is $57.7 \mathrm{Mt}$ (P65CAP SHR07).

In terms of endogenous factors, though the carbon emissions reduction rates of different sectors under the SHRbau scenario are even, the sectoral potentials to cut carbon emissions are different. Both figure 5(a) and 5(b) show a similar trend that for most sectors a higher potential on autonomous carbon abatement leads to a lower carbon abatement cost. The metal smelting sector has the strongest potential of autonomous carbon reduction (a $41 \%$ intensity decrease on the $x$-axis) so that its carbon abatement cost is the lowest among all the sectors. On the other hand, the aviation sector holds the least potential of autonomous carbon emissions reduction (a 1.63\% intensity decrease on the $x$-axis), which makes this sector have a considerably high carbon abatement cost under both allocation methods (300.7 USD/t under SHRbau and 650.1 USD/t under SHR07, respectively).

However, an obvious exception is the petrol oil sector, which undertakes a considerably high carbon abatement cost at 522.7 to $573.4 \mathrm{USD} / \mathrm{t}$ regardless of its moderate autonomous carbon abatement potential. This phenomenon could be explained from the perspective of the efficiency effect, namely the technological progress.

In the CGE framework, sectoral technological progress can be represented by the substitution between energy input and capital input. Figure 6 shows the changes of sectoral capital/energy substitution from the corresponding scenarios to $\mathrm{BaU}$ in 2030. The capital/energy input ratios of each sector under the corresponding scenarios are divided by that under the BaU scenario and presented on the $y$-axis with logarithmic coordinates. That is to say, if technological progress takes place in a sector, this index should be larger than 1. As shown in figure 6, the capital/energy input ratios of most sectors increase, so that energy can be saved by developing more advanced and efficient equipment, thus reducing the carbon emissions and adapting to the abatement target of the mitigation scenarios. However, the petrol oil sector, whose energy input has already tremendously exceeded the capital input under the $\mathrm{BaU}$ scenario, fails to achieve any improvement on technological progress compared to the $\mathrm{BaU}$ scenario, and even reduces its capital/energy ratio, showing an increasing dependence on energy input under the mitigation scenarios. As an energy transforming sector, it is indeed difficult to substitute energy input for capital input, thus the heavy dependence on energy input is 
possibly the key to its abnormally high carbon abatement cost. Additionally, figure 6 also indicates that the technological progress of the power generation sector is poorer under the SHR07 scenario, which could be a possible reason for the change of its trading strategy in section 3.4.2.

<insert Figure 6 here>

In general, there is an enormous imbalance among different sectors in terms of carbon abatement burden, even under an evenly distributed abatement target.

\subsection{Carbon market impacts}

The simulated carbon prices in 2030 would be 124.3, 161.2, 189.9, 147.2 USD/t under the four representative scenarios, P55ET SHRbau, P65ET SHRbau, P75ET SHRbau and P65ET SHR07, respectively. The carbon prices of different regional abatement targets under the SHRbau allocation method indicate that a stricter abatement target will lead to a higher carbon price. This trend is caused by the fact that a stricter abatement target reduces the volume of the circulating allowances in the market and consequently, boost the price.

\subsubsection{Market scale}

Figure 7 shows the trading volumes, trade monetary values, and their shares to the total emissions and GDP values under the four representative scenarios. The trading volumes of the four representative scenarios are 14.9, 12.6, 12.0, 29.4 Mt, and the trade monetary values are 1.9, 2.0, 2.3, 4.3 bilUSD.

$<$ insert Figure 7 here $>$

In terms of the impact on regional abatement target, the results show a decreasing trend of trading volumes and an increasing trend of monetary values when regional abatement target increases. The stricter abatement target reduces the surplus allowances in the market, leading to a decrease of the trading volume. However, a higher carbon price increases the expense of all the sectors, resulting in increasing trade monetary values. Furthermore, the proportions of trading volumes and trade monetary values have the same increasing trend, indicating that the weight of the carbon market in the whole economic system would increase with the carbon abatement target.

In terms of the impact of allocation method, the scale of carbon market under the P65 SHR07 scenario doubles the one under the P65 SHRbau scenario. The allocation of SHR07 is based on the data in 2007, while the allocation of SHRbau is based on the data simulated in 2030. Therefore, the allocation of the initial allowances is more similar to the actual demand under the SHRbau than the SHR07, so that more adjustments, namely transaction, will take place in the carbon market under SHR07. A detailed explanation on the sectoral level is presented in the next section.

\subsubsection{Sectoral trading}

Figure 8 presents the sectoral trading volumes of the four representative 
scenarios in detail.

The allocation method has a significant impact on sectoral trading strategies. Under SHRbau, the aviation sector is the main buyer, while the metal smelting sector and chemicals sector are the main sellers. Under SHR07, the metal smelting sector is the dominant seller, while the power generation, chemicals, and aviation sectors are the main buyer. It is worth mentioning that the trading volumes of the metal smelting sector and power generation sector decrease significantly under the SHRbau allocation method, which could be the key to the huge carbon market scale difference. In terms of the metal smelting sector, the initial allowance for this sector is $35.8 \mathrm{Mt}$ under the P65 SHRbau scenario and 58.0 Mt under the P65 SHR07 scenario, which indicates a considerable surplus for the metal smelting sector. In terms of the power generation sector, figure 6 shows that its technological progress is poorer under the P65 SHR07 scenario. Thus more allowances are needed. In addition, the carbon price under the P65 SHR07 scenario is lower than the one under the P65 SHRbau scenario due to the zero abatement cost of the metal smelting sector, indicating that the power generation sector can purchase carbon allowance with a lower price.

$<$ insert Figure 8 here>

On the other hand, the impact on trading strategies from different regional abatement targets is less obvious. The main buyers and sellers under the SHRbau allocation method remain the same. However, the power generation sector changes its trading strategy under a more stringent abatement target, switching from a buyer under P65 SHRbau to a seller under P75 SHRbau. The output of the power generation sector consists of its own production and the electricity imported from outside of Shanghai. The electricity import data of the CGE model shows that the power generation sector increases the share of imported electricity in the overall output instead of purchasing more allowances if regional abatement target increases. Furthermore, a stricter abatement target pushes those sectors with high energy demands to reduce their outputs, leading to a weaker demand of the power generation. Consequently, the power generation sector decreases the allowance purchasing and becomes a seller under the P75ET SHRbau scenario.

\subsection{Sectoral impacts}

There are three measures for the carbon trading participating sectors to meet the carbon cap, including technological improvement, production growth reduction and allowance purchase. It is shown in Figure 6 that the initial allocation method has little impact on sectoral technological progress. Thus the trade-off between reducing production growth and purchasing allowance determines how a sector will respond to the cap-and-trade scheme. 
Figure 9 shows the trade-offs between production growth reduction and allowance purchase. The $x$-axis represents the share of allowance that is purchased from or sold to the carbon market, showing how much extra carbon emission a sector is willing to release regardless of extra costs, or how much allowance is surplus for the actual demand of a sector. The y-axis represents the reduction rate of production relative to $\mathrm{BaU}$, showing how much impact the sector takes under the abatement target.

<insert Figure 9 here $>$

Among the buyer sectors in Figure 9, the aviation sector has a rather high carbon abatement cost and weak autonomous carbon emissions reduction potential. The aviation sector, which has a 1.63\% carbon emissions intensity reduction from 2007 to 2030 in BaU, will purchase $11.1 \mathrm{Mt}$ allowance (48.3\% of its total emission), and would consequently achieve a $55.8 \%$ production growth relative to $\mathrm{BaU}$. The aviation sector relies heavily on conventional fuels and faces many obstacles in putting the renewable energy into use. Besides, the aviation sector offers transportation services to households, which means there will be lower impact on the demand for the aviation despite its increasing prices. Therefore, the aviation sector would be a main buyer in the future carbon trading market and purchase allowances in order to maintain its production growth.

The petrol oil sector, with the highest carbon abatement cost, would experience a huge production loss $(-36.3 \%$ and $-37.4 \%)$ among all the buyers. The petrol oil sector is an energy transforming sector, so that its production is related not only to the supply of upstream sectors but also to the demand of downstream sectors. The carbon cap will affect both sides and augment the impact on the petrol oil sector. Additionally, the difficulties in technological progress lead to a heavy dependence on energy input and an increasing amount of energy consumption.

The power generation sector would suffer the greatest loss (-36.4\%) under the P65ET SHRbau scenario and a considerable loss (-32.0\%) under the P65ET SHR07 scenario, while this sector shows an inactive response in the carbon market. There are two reasons for such a result. One is that the power generation sector is an energy supply sector. Electricity is mainly consumed by the downstream energy-intensive sectors such as the metal smelting and chemicals sectors. However, the production shrink of the downstream sectors under mitigation scenarios will lead to less demand for electricity. Another reason has already been mentioned in section 3.4.2, namely, the power generation sector will purchase electricity from outside of Shanghai. The electricity generated outside Shanghai has lower carbon emissions intensity with the application of renewable energy, and thus, having a lower price. Such 
an action would inevitably reduce the production of domestic electricity, which could result in the inactive allowance purchase of the power generation sector.

The metal smelting and chemicals are the two sectors whose strategies may change significantly under different allocation methods. The metal smelting sector would experience a $6.8 \%$ to $7.3 \%$ production loss, but it is the main seller under the P65ET SHRbau scenario and the dominant seller under the P65ET SHR07 scenario, which could be attributed to the differences in the initial allowances allocation. Since Figure 5 shows that the metal smelting sector has the greatest autonomous carbon emissions intensity reduction and highest carbon abatement potential, it would be appropriate for the metal smelting sector to sell its surplus allowance for extra profits. The chemicals sector would experience a $22.1 \%$ to $24.4 \%$ production loss. The initial allowance for chemicals sector is more stringent under SHR07 so that it will switch to a buyer under the P65ET SHR07 scenario.

Comparing figures $9(a)$ and $9(b)$, the impacts on different sectors seem to have a significant disparity. However, it is worth mentioning that different settings of initial allowances allocation do not generate significant impacts on sectoral outputs but greatly affect the emissions trading behaviors. To be specific, the supply-demand relation is determined once a regional abatement target is set, and sectors tend to adjust the possession of the allowances through the carbon trading market, in order to meet the determined outputs.

\section{Discussions}

\subsection{Policy implications}

The Chinese national carbon trading market was established in 2017. Based on the main findings from this study, several policy recommendations are proposed.

Firstly, it is important to set up appropriate abatement targets to different sectors at the regional level so that the overall regional abatement target can be achieved. Particularly, those sectors with higher abatement potentials and lower costs should be the prioritized sectors so that their mitigation potentials can be achieved to the maximum. In the case of Shanghai, such sectors include both chemical and petrol oil sectors, indicating that both sectors will be the potential losers with strict carbon emissions reduction policies. It will be rational for the city of Shanghai to relocate such industries to other areas of Yangtze Delta so that the city can attract more service or high-tech manufacturing industries. As the national financial and shipping center, Shanghai can easily enhance its financial service and logistics businesses. Also, Shanghai is home to many key universities and research institutes, and can encourage intellectual manufacturing and information and communication technology businesses. These businesses have less carbon emissions and other environmental emissions, while generating higher revenues. In addition, the 
emissions trading mechanism is capable of compensating for those sectors with lower carbon reduction potentials, such as the aviation sector. To cope with the increasing demand on air transportation, the aviation sector should be supported and protected. Nevertheless, over-allocation would bring a price shock when free allocation is applied, thus a pre-granting system should be applied rather than directly offering more initial allowance to the aviation sector. A certain proportion of the initial allowances is granted to the sector and there will be a refund for any overpayment or a supplemental payment for any deficiency. This means that local government could avoid the potential price shock from over-allocation, while the overall loss of this sector can also be reduced. Another key finding is that historical emission together with the industrial developing trend should be considered when preparing the initial emissions allowance. With the phase-out of some energy-intensive sectors, such as the metal smelting sector, the initial allocation of emissions allowance to these sectors should be carefully designed so that over-allocation issue can be avoided.

Secondly, it is critical to further optimize energy structure in Shanghai. The finding of this study indicates that power generation sector will be the most affected sector under different regional abatement targets. Currently, Shanghai's power generation sector is mainly coal-based, generating not only carbon emissions but also air pollutants. However, it is more expensive and limited to develop cleaner and renewable energy in Shanghai. Consequently, it will be rational to import cleaner energy from the neighboring regions. This is challenging because it requires the great improvement of national power grids so that the transmission capacity can be enhanced. In addition, further efforts should be made in order to further optimize local energy structure. For instance, Shanghai is one leading city on applying geothermal power (Geng et al., 2013b), but its current application of geothermal power is still limited. Applications of such technology can be encouraged by issuing stricter green building standards. Also, Shanghai is a seaport city and it has a great potential to apply offshore wind power. Moreover, the substitution of coal for natural gas is another measure to further reduce the carbon emissions intensity.

Thirdly, it is necessary to promote low carbon consumption in Shanghai. It was projected in this study that Shanghai would encounter a significant welfare loss (-8.9\% compared to $\mathrm{BaU}$ ) under the $65 \%$ carbon intensity abatement target. Production and consumption are always interlinked. Without controlling the increasing consumption, it is difficult to reduce the overall production. In this regard, low carbon consumption can help reduce the overall productionbased emissions. However, due to relatively lower environmental awareness, both low carbon commodities and services are not widely accepted by the local citizens (Tian et al., 2016). Therefore, the Shanghai government should 
initiate more capacity-building efforts, such as TV and radio promotions, regular workshops, billboards and internet, so that more citizens can learn how to change their behaviors. In addition, governmental subsidies can further encourage citizens to engage in low carbon development. Subsidies would come from the revenues of environmental taxations or allowances auctions, and transfer to the households. Such an action is known as revenue return, which could reduce the negative macroeconomic impacts (Lennox et al., 2010), thus alleviate the welfare loss. However, careful design of such policies is crucial. For instance, Shanghai is the first Chinese city to subsidize the new energy vehicles. But the subsidy is designed only for purchasing, there is no economic driver for the actual drive. Also, from a life cycle point of view, new energy vehicles do not really reduce the overall emissions when the local power grid is mainly coal-based (Geng et al., 2013a).

Last but not least, the carbon trading market should be carefully managed. A mature carbon trading market should be based upon a transparent monitoring, reporting and verification system. Without accurate data, it would be impossible for any transactions. In this regard, China's National Development Reform Commission (NDRC) planned to cover eight sectors when designing its national carbon trading market, but finally only chose the electricity sector mainly because of the poor access to accurate data of historical sectoral emissions. Enterprises participating in the EU-ETS are required to report their carbon emissions data annually to their governments. However, such a policy does not exist in China due to outdated carbon emissions accounting methods and poor financial capabilities of small-sized enterprises. Therefore, it is crucial to set up a well-operating report regime to improve the transparency and accuracy of historical carbon emissions data. Such a measure can consequently improve the equity and efficiency of allowances allocation. Furthermore, the punishment policies on carbon trade are weak and ineffective. For example, those enterprises that fail to meet the carbon cap in due time will only be charged for a fine ranging from 50 to 100 thousand RMB (currently 1 USD=6.3 RMB). Such a low fine does not provide any adequate driver to further reduce carbon emissions. Hence, stricter policies are expected to be released. Also, to strengthen the monitoring of a carbon trading market is important, including the prices, trading volumes, so that any illegal activities can be quicky recognized and revised accordingly. In addition, to increase the enforcement capacities of relevant officials is critical so that those enterprises engaging in carbon transactions can seriously follow the rules.

\subsection{Limitations and future work}

This study focuses on intra-provincial trade. With the fact of that the 
Chinese national carbon trading market was established in late 2017, it would be necessary to evaluate the impact of the national carbon trading. This will require significant data, which could be time-consuming.

The allocation method of the initial allowances in this study also has several limitations. In the national carbon trading market in China, the benchmark method will be applied together with a grandfathering method. It could be further switched to the auction method. Under such a circumstance, the sectoral impact of those innovative allocation methods remains to be further investigated.

Furthermore, the definition of welfare loss in this study is relatively narrow, which is the change in consumption of commodities and services. In fact, several studies proposed that climate change mitigation could lead to numerous co-benefits, such as increasing people's welfare with the improvement of air quality and human health (Bell et al., 2008; McCollum et al., 2013; Nemet et al., 2010; West et al., 2013). In this regard, Cifuentes and his colleages (2001) found that considerable local public health benefits could be achieved through GHG mitigation by reducing fossil fuel combustion. Thompson and his colleages (2014) found that human health-related air quality improvement could save a huge amount of public budget. In addition, Ciscar and his colleages (2011) found that climate change would cause damages in agriculture, river floods, coastal areas, tourism, and human health. Therefore, it may be more appropriate to investigate the co-benefits from climate change mitigation in the future so that more valuable policy insights can be obtained to promote the whole society toward low carbon development.

\subsection{Comparisons with other similar studies}

The predicted carbon price in 2030 in Shanghai is much higher than the current price level of about $30 \mathrm{RMB} / \mathrm{t}$ (about $5 \mathrm{USD} / \mathrm{t}$ ). There are two reasons. Firstly, the abatement target for Shanghai will be much more stringent in 2030, leading to a stronger demand on the allowances. Secondly, the carbon trading market in Shanghai is still in its early stage, where the participating sectors are less enthusiastic and the transparency and accuracy of relevant data are less mature. The initial allowances in the current market have not yet experienced complete competition, leading to the huge difference between the current price and the predicted price in 2030.

In terms of other studies, Zhang and his colleages (2013) applied a CGE model to study the economic impact of the national market, in which the predicted carbon price under the provincial target scenario would be 16 to 60 USD/t, and the welfare loss in Shanghai would be less $1 \%$. Another study from $\mathrm{Wu}$ and his colleages (2016a) found that the welfare loss would also be less than $1 \%$. The differences in those studies could be attributed to the simulation 
year (2020) with a less stringent abatement target settings based on the $12^{\text {th }}$ FYP (Five Year Plan), and a nationwide carbon market. Wu and his colleages (2016b) found that the GDP loss of Shanghai would be $1.7 \%$ in 2030, which is lower than the result of this study. The reason for this difference could be the different settings of exogenous variables of BaU. In addition, Zhou and his colleages (2015) found another possible reason for the switch of electricity sector from buyer to seller, namely, the large-scale deployment of non-fossil fuel energy.

\section{Conclusions}

In order to predict the future impact of carbon cap-and-trade scheme in Shanghai in 2030, this study applies a multi-sector, 2-region, recursive dynamic CGE model. Several scenarios were designed to evaluate the possible impacts on the macro-economy, carbon trading markets and participating sectors. The key findings are summarized as follows. The carbon cap-andtrade scheme would cause an inevitable loss of both macro-economy and welfare, but carbon trade could compensate for the losses and redress the imbalance of initial allowances allocation. The carbon market scale under the P65ET SHR07 scenario would be $29.4 \mathrm{Mt}$, and exceed the carbon market scale under the P65ET SHRbau scenario (with a value of $12.6 \mathrm{Mt}$ ). The carbon price would be $161.2 \mathrm{USD} / \mathrm{t}$ and $147.2 \mathrm{USD} / \mathrm{t}$ under the two representative scenarios. At the sectoral level, the power generation sector and the petrol oil sector would experience the greatest output losses, while the metal smelting sector would have the highest potential of autonomous carbon emissions reduction and become the main seller of emission allowance. Furthermore, the initial allowances allocation under a certain abatement target would hardly affect the sectoral production given that full carbon trade is guaranteed, but it will affect the trading behaviors in the carbon trading market.

\section{Acknowledgement}

This study was supported by the Natural Science Foundation of China (71690241, 71704005, 71325006, 5171101576), the Fundamental Research Funds for the Central Universities through Shanghai Jiao Tong University (16JCCS04), the Shanghai Municipal Government (17XD1401800), and the Startup Research Fund of College of Environmental Science and Engineering at Peking University. 


\section{References}

Alberola, E., Chevallier, J., Chèze, B.t., 2008a. Price drivers and structural breaks in European carbon prices 2005-2007. Energy Policy 36(2), 787-797.

Alberola, E., Chevallier, J., Cheze, B., 2008b. The EU emissions trading scheme: the effects of industrial production and $\mathrm{CO} 2$ emissions on European carbon prices. International Economics 119(4), 95-128.

Albers, S., Bühne, J.-A., Peters, H., 2009. Will the EU-ETS instigate airline network reconfigurations? Journal of Air Transport Management 15(1), 1-6.

Bell, M.L., Davis, D.L., Cifuentes, L.A., Krupnick, A.J., Morgenstern, R.D., Thurston, G.D., 2008. Ancillary human health benefits of improved air quality resulting from climate change mitigation. Environ Health 7, 41.

Chen, W., Li, Y., Huang, G., Chen, X., Li, Y., 2010. A two-stage inexact-stochastic programming model for planning carbon dioxide emission trading under uncertainty. Applied Energy 87(3), 1033-1047.

Chen, Y., Sijm, J., Hobbs, B.F., Lise, W., 2008. Implications of $\mathrm{CO}$ (2) emissions trading for short-run electricity market outcomes in northwest Europe. Journal of Regulatory Economics 34(3), 251-281. Cheng, B., Dai, H., Wang, P., Xie, Y., Chen, L., Zhao, D., Masui, T., 2016. Impacts of low-carbon power policy on carbon mitigation in Guangdong Province, China. Energy Policy 88, 515-527.

Cheng, B., Dai, H., Wang, P., Zhao, D., Masui, T., 2015. Impacts of carbon trading scheme on air pollutant emissions in Guangdong Province of China. Energy for Sustainable Development 27, 174-185.

Cifuentes, L., Borja-Aburto, V.H., Gouveia, N., Thurston, G., Davis, D.L., 2001. Hidden health benefits of greenhouse gas mitigation. Science 293(5533), 1257-1259.

Ciscar, J.C., Iglesias, A., Feyen, L., Szabo, L., Van Regemorter, D., Amelung, B., Nicholls, R., Watkiss, P., Christensen, O.B., Dankers, R., Garrote, L., Goodess, C.M., Hunt, A., Moreno, A., Richards, J., Soria, A., 2011. Physical and economic consequences of climate change in Europe. Proc Natl Acad Sci U S A 108(7), 2678-2683.

Coase, R.H., 1937. The nature of the firm. economica 4(16), 386-405.

Cong, R.-G., Wei, Y.-M., 2010. Potential impact of (CET) carbon emissions trading on China's power sector: A perspective from different allowance allocation options. Energy 35(9), 3921-3931.

Cong, R.-G., Wei, Y.-M., 2012. Experimental comparison of impact of auction format on carbon allowance market. Renewable and Sustainable Energy Reviews 16(6), 4148-4156.

Convery, F., Ellerman, D., Perthuis, C.D., 2008. The European Carbon Market in Action: Lesson from the First Trading Period. http://web.mit.edu/globalchange/www/ECM_InterimRpt_March08.pdf.

Dai, H., 2012. Integrated assessment of China's provincial low carbon economy development towards 2030: Jiangxi province as an example. Tokyo Institute of Technology.

Denny, E., O'Malley, M., 2009. The impact of carbon prices on generation-cycling costs. Energy Policy 37(4), 1204-1212.

Eggleston, H., Buendia, L., Miwa, K., Ngara, T., Tanabe, K., 2006. IPCC guidelines for national greenhouse gas inventories. Institute for Global Environmental Strategies, Hayama, Japan 2, 48 56.

Ellerman, A.D., Buchner, B., 2006. Over-Allocation or Abatement?A Preliminary Analysis of the EU Emissions Trading Scheme Based on the 2006 Emissions Data. 
http://web.mit.edu/globalchange/www/MITJPSPGC_Rpt141.pdf.

Ellerman, A.D., Buchner, B., Carraro, C., 2008. Allocation in the EU Emissions Trading Scheme: Rents, Rights, and Fairness. Cambridge University Press, forthcoming.

ENVIRONOMIST, 2017. China carbon market report.

Exchange, S.E.E., 2017. Shanghai carbon market report.

Fujimori, S., Masui, T., Matsuoka, Y., 2014. Development of a global computable general equilibrium model coupled with detailed energy end-use technology. Applied Energy 128, 296 306.

Fujimori, S., Masui, T., Matsuoka, Y., 2015. Gains from emission trading under multiple stabilization targets and technological constraints. Energy Economics 48, 306-315.

Gao, G., Chen, S., Yang, J., 2015. Carbon emission allocation standards in China: A case study of Shanghai city. Energy Strategy Reviews 7, 55-62.

Geng, Y., Ma, Z., Xue, B., Ren, W., Liu, Z., Fujita, T., 2013a. Co-benefit evaluation for urban public transportation sector-a case of Shenyang, China. Journal of cleaner production 58, 82-91.

Geng, Y., Sarkis, J., Wang, X., Zhao, H., Zhong, Y., 2013b. Regional application of ground source heat pump in China: a case of Shenyang. Renewable and Sustainable Energy Reviews 18, 95-102. Hübler, M., Voigt, S., Löschel, A., 2014. Designing an emissions trading scheme for China-An upto-date climate policy assessment. Energy Policy 75, 57-72.

Jiang, J., Xie, D., Ye, B., Shen, B., Chen, Z., 2016. Research on China's cap-and-trade carbon emission trading scheme: Overview and outlook. Applied Energy 178, 902-917.

Kanen, J.L.M., 2006. Carbon trading and pricing. Environmental Finance Publications

Lennox, J.A., Van Nieuwkoop, R., 2010. Output-based allocations and revenue recycling: Implications for the New Zealand Emissions Trading Scheme. Energy Policy 38(12), 7861-7872.

Li, J.F., Wang, X., Zhang, Y.X., Kou, Q., 2014. The economic impact of carbon pricing with regulated electricity prices in China—An application of a computable general equilibrium approach. Energy Policy 75, 46-56.

Liu, Z., Geng, Y., Dong, H., Wilson, J., Micic, T., Wu, R., Cui, X., Qian, Y., You, W., Sun, H., 2018. Efficient distribution of carbon emissions reduction targets at the city level: A case of Yangtze River Delta region. Journal of Cleaner Production 172, 1711-1721.

McCollum, D.L., Krey, V., Riahi, K., Kolp, P., Grubler, A., Makowski, M., Nakicenovic, N., 2013. Climate policies can help resolve energy security and air pollution challenges. Climatic Change 119(2), 479 494.

NBS, 2007. Input-output tables of china 2007 (in Chinese). China Statistics Press.

NBS, 2008. China energy statistical year book 2008 (in Chinese). China Statistics Press.

NBS, 2012a. China energy statistical year book 2012 (in Chinese). China Statistics Press.

NBS, 2012b. Input-output tables of china 2012 (in Chinese). China Statistics Press.

Nemet, G.F., Holloway, T., Meier, P., 2010. Implications of incorporating air-quality co-benefits into climate change policymaking. Environmental Research Letters 5(1).

Pachauri, R.K., Allen, M.R., Barros, V.R., Broome, J., Cramer, W., Christ, R., Church, J.A., Clarke, L., Dahe, Q., Dasgupta, P., 2014. Climate change 2014: synthesis report. Contribution of Working Groups I, II and III to the fifth assessment report of the Intergovernmental Panel on Climate Change. IPCC.

Rutherford, T.F., 1999. Applied general equilibrium modeling with MPSGE as a GAMS subsystem: An overview of the modeling framework and syntax. Computational economics 14(1), 1-46. 
Soleille, S., 2006. Greenhouse gas emission trading schemes: a new tool for the environmental regulator's kit. Energy Policy 34(13), 1473-1477.

Tang, L., Shi, J., Bao, Q., 2016. Designing an emissions trading scheme for China with a dynamic computable general equilibrium model. Energy Policy 97, 507-520.

Tang, W., Wu, L., 2013. Efficiency or equity? Simulating the carbon emission permits trading schemes in China based on an inter-regional CGE model, 16th Annual Conference on Global Economic Analysis.

Thompson, T.M., Rausch, S., Saari, R.K., Selin, N.E., 2014. A systems approach to evaluating the air quality co-benefits of US carbon policies. Nature Climate Change 4(10), 917-923.

Tian, X., Geng, Y., Dai, H., Fujita, T., Wu, R., Liu, Z., Masui, T., Yang, X., 2016. The effects of household consumption pattern on regional development: A case study of Shanghai. Energy 103, 49-60.

Voorspools, K., 2006. European emissions 2005: uncertainties, confusion, blanks and hope. Energy \& Environmental Markets: special Report, Fortis Bank. Energy and Carbon Market Analysis 15.

Wang, K., Wang, C., Chen, J., 2009. Analysis of the economic impact of different Chinese climate policy options based on a CGE model incorporating endogenous technological change. Energy policy 37(8), 2930-2940.

Wang, P., Dai, H.-C., Ren, S.-y., Zhao, D.-q., Masui, T., 2015. Achieving Copenhagen target through carbon emission trading: Economic impacts assessment in Guangdong Province of China. Energy 79, 212-227.

Wei, C., Ni, J., Du, L., 2012. Regional allocation of carbon dioxide abatement in China. China Economic Review 23(3), 552-565.

West, J.J., Smith, S.J., Silva, R.A., Naik, V., Zhang, Y., Adelman, Z., Fry, M.M., Anenberg, S., Horowitz, L.W., Lamarque, J.F., 2013. Co-benefits of Global Greenhouse Gas Mitigation for Future Air Quality and Human Health. Nat Clim Chang 3(10), 885-889.

Wu, J., Fan, Y., Xia, Y., 2016a. The Economic Effects of Initial Quota Allocations on Carbon Emissions Trading in China. The Energy Journal 37(01).

Wu, R., Dai, H., Geng, Y., Xie, Y., Masui, T., Tian, X., 2016b. Achieving China's INDC through carbon cap-and-trade: Insights from Shanghai. Applied Energy 184, 1114-1122.

Xu, X., Zhang, W., He, P., Xu, X., 2017. Production and pricing problems in make-to-order supply chain with cap-and-trade regulation. Omega 66, 248-257.

Yu, P., Qin, Z., 2011. Using Carbon Trading to Seize the Commanding Heights of Economic Development, in: Zhang, W. (Ed.) 2010 International Conference on Energy, Environment and Development. pp. 74-78.

Zhang, D., Rausch, S., Karplus, V.J., Zhang, X., 2013. Quantifying regional economic impacts of CO 2 intensity targets in China. Energy Economics 40, 687-701.

Zhang, J.-J., Nie, T.-F., Du, S.-F., 2011. Optimal emission-dependent production policy with stochastic demand. International Journal of Society Systems Science 3(1-2), 21-39.

Zhang, Y.-J., Wei, Y.-M., 2010. An overview of current research on EU ETS: Evidence from its operating mechanism and economic effect. Applied Energy 87(6), 1804-1814.

Zhang, Z.X., 1998. Macroeconomic effects of CO 2 emission limits: a computable general equilibrium analysis for China. Journal of policy modeling 20(2), 213-250.

Zhou, P., Zhang, L., Zhou, D.Q., Xia, W.J., 2013. Modeling economic performance of interprovincial CO2 emission reduction quota trading in China. Applied Energy 112, 1518-1528.

Zhou, S., 2015. Economic and environmental impacts of the Shanghai carbon emission trading: 
based on CGE model analysis. Adv. Clim. Change Res 11, 144-152. 